\title{
Environmental tobacco smoke exposure and health disparities: 8-year longitudinal findings from a large cohort of Thai adults
}

Thanh Tam Tran ${ }^{1 *}$, Vasoontara Yiengprugsawann ${ }^{1}$ Dujrudee Chinwong ${ }^{2}$, Sam-ang Seubsman ${ }^{3}$ and Adrian Sleigh ${ }^{1}$

\begin{abstract}
Background: In rich countries, smokers, active or passive, often belong to disadvantaged groups. Less is known of tobacco patterns in the developing world. Hence, we seek out to investigate mental and physical health consequences of smoke exposure as well as tobacco-related inequality in transitional middle-income Thailand.

Methods: We studied a nationwide cohort of 87,151 middle-aged and older adults that we have been following for eight years (2005-2013) for emerging chronic diseases. Logistic regression was used to identify attributes associated with passive smoke exposure. Longitudinal associations between smoke exposure and wellbeing (SF-8) or psychological distress (Kessler 6) were investigated with multiple linear regression or multivariate logistic regression analysis.

Results: A high proportion of cohort members, especially females, were passive smokers at home and at public transport stations; males were more exposed at workplace and recreational places. We observed a social gradient with more passive smoking in poorer people. We also observed a dose response relationship linking graded smoke exposures (current, former, passive, non-exposed) to less wellbeing and more psychological distress ( $p$-trend $<0.001$ ). Female smokers in general had less wellbeing and more distress.

Conclusion: Our findings add to current knowledge on the impact of active and passive smoking on health in a transitional economy. Promotion of smoking cessation programs both in public and at home could also potentially reduce adverse disparities in health and wellbeing in middle and lower income settings such as Thailand.
\end{abstract}

Keywords: Environmental tobacco smoke, Thailand, Cohort study, Psychological distress, Wellbeing, Health-related quality of life

\section{Background}

Active or passive, smoking kills and there is no safe level of exposure to it $[1,2]$. The World Health Organization has estimated that tobacco kills nearly 6 million people each year and, among them, $10 \%$ were due to second hand smoke $[3,4]$. It is well-established that active smoking is associated with many deadly diseases, including diabetes, cardiovascular and respiratory illnesses, as well as lung and other cancers [3]. Smokers also have vastly reduced health-related quality of life [5-7] and more mental illness [8,9]. Evidence against passive smoking is also compelling and there is a clear scientific

\footnotetext{
* Correspondence: tam.tran@anu.edu.au

'Research School of Population Health, College of Medicine, Biology and Environment, The Australian National University, Building 62, Mills Rd, Acton 2601, Canberra, Australia

Full list of author information is available at the end of the article
}

consensus that environmental tobacco smoke can cause serious and fatal diseases in non-smoking adults and children [10].

In developing countries, information on passive smoking is scarce. Some developing countries have responded to the challenge of tobacco control and much can be learnt from their experience. Thailand is such a country and is well-known for its pioneering tobacco control policies that have been progressively implemented since 1992 when the parliament passed the Tobacco Products Control Act, banning advertising, promotion and sponsorship as well as sale to minors. By 2005, the Ministry of Health had banned display of cigarette at point of sale and had high impact horror pictures on all cigarette packages. In 2007, hotel lobbies, pubs and bars were declared non-smoking areas [11]. 
Despite the gains made since 1992, social disparities in smoking rates among Thais remain. For example, people belonging to low income or educational groups have highest smoking rates and those with highest income or educational levels have lowest smoking rates [12]. The laws limiting environmental smoke in 2007 are not well enforced [11]. Accordingly, there is still a major problem and little information about the effect of passive smoking. Given the high rate of smoking among those in socioeconomically disadvantaged groups, it seems likely that non-smokers of those same groups are disproportionately exposed to passive smoking. Passive smoking is involuntary and thus is an issue of equity and justice.

Gender disparity in passive smoking is also a known issue especially in patriarchal societies where gender differences in power may lead to women unwillingly but unavoidably exposed to environmental tobacco smoke (ETS) from male smokers [10]. Female passive smokers have also been shown to have worse health outcomes from ETS than male counterparts. They also reported more respiratory symptoms and worse self-rated health [13].

In this study, we investigate the effects of passive smoking on psychological distress and wellbeing in Thailand. Study participants are members of a large nationwide cohort that has been followed for a decade for research on changing disease patterns. Our study is one of the first to focus on environmental smoke and its effect on mental health, wellbeing and quality of life. It is also one of the first studies of ETS in a middle income Asian setting.

\section{Methods}

\section{Study population and data collection}

This report is part of an over-arching Thai Cohort Study (TCS) project that analyses the health-risk transition underway in Thailand. This transition involves changing health risks and outcomes of the Thai population as the country moves on from its traditional problems with infectious diseases and maternal-child mortality to emerging chronic conditions and injury. Participants of the TCS included 87,151 distance learning communityembedded students of Sukhothai Thammathirat Open University in 2005. Self-reported mail-out questionnaires with free return postage collected data at three time points: baseline 2005, follow-up 2009, and follow-up 2013. For this report, we use information from the first (2005) and the latest follow-up (2013).

Cohort characteristics have been reported extensively: in brief, TCS members represented well the adult Thai population for median age, average income, geographical distribution, religion and ethnic diversity [14-16]. Compared to the general population there was a small excess of females (54.3\%), and of urban dwellers $(51.8 \%$ vs $31.1 \%)$. Cohort members are better educated than the general population and are ahead of their Thai compatriots on the health-risk transition path, representing aspirational "Thais of tomorrow".

\section{Exposures, outcomes and confounders}

TCS questionnaires collect data on a wide range of topics including demographic, socioeconomic and geographic information, health status, disease history, healthrisk behaviours, health service use, social links and support, injuries, and family background.

Participants reported their smoking status (never smoker, former smoker or current smoker) at baseline (2005) and again at 4- and 8-year follow-ups (2009, 2013). At baseline in 2005, participants were also asked if they were exposed to smoke at home, in a recreational place, in the workplace, at a public transport station (e.g. train/bus station) or any other place. If they answered "yes" to any one of these locations they were classified as a passive smoker.

For analysis, participants were further classified into 4 different smoking groups as follows: 1) control group (non-exposure) - consistent never smokers on all three assessments who reported no exposure to passive smoke at baseline; 2) passive smokers - consistent never smokers in all three assessments who reported exposure to passive smoke at baseline; 3) former smoker (nonsmoker in 2013 and smokers in at least one of the two previous assessments); 4) current smoker (in 2013 regardless of smoking status in 2009 or 2005) (Fig. 1).

Wellbeing was assessed in 2013 (i.e. at the end of the 8-year follow-up) using standardised Medical Outcome Study Short-Form 8 (MOS SF- ${ }^{\mathrm{mm}}$ ) Health Survey $[17,18]$. The original Short Form instrument (SF-36) is highly responsive to active smoking and is a sensitive marker for smoking related conditions $[5,7,19]$. SF-8 consists of eight questions representing the following eight domains: general health, physical functioning, daily physical, bodily pain, vitality, social functioning, mental health, and daily emotional [17]. Responses were on an ordinal 5 or 6 point scale. Physical Component Summary (PCS) score and Mental Component Summary (MCS) score were computed according to the SF-8 guidelines by first assigning international weights to each domain value before the domain scores were summed and a constant was then added. The scores were standardised using a norm-based scoring methods for a normal population with a mean score of 50 and standard deviation of 10 . Higher scores represent better health outcomes.

Psychological distress was also measured in 2013 using standard Kessler 6 (K6) which has high validity for grading anxiety-mood disorders [20]. K6 consists of six questions "In the past 4 weeks, how often did you feel: 1) so sad nothing could cheer you up; 2) nervous; 3) restless or fidgety; 4) hopeless; 5) everything was an effort; and 6) 


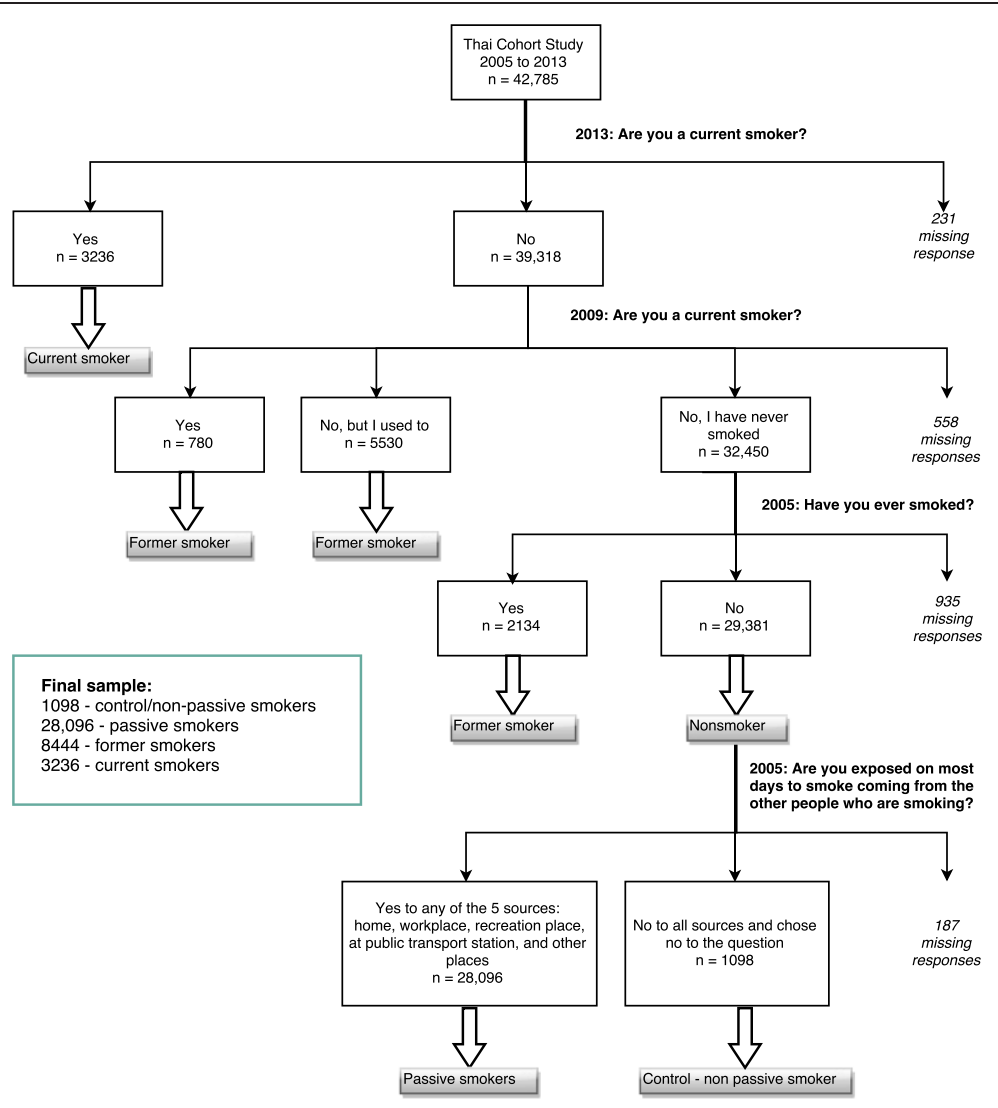

Fig. 1 Selection of the analysed population from the Thai Cohort Study, 2005-2013

worthless. Each question of this instrument uses a 5category Likert response scale. Participants were given a score of 1 if answering "none", 2 "a little", 3 "some", 4 "most", and 5 for answering "all of the time". The scores for all the questions were then totalled ranging from 6 to 30 with higher scores representing worse health outcomes. We combined the standard moderate and serious psychological distress categories to create a dichotomous outcome ( $<14$ : no distress, $\geq 14$ : psychological distress).

Information was also gathered on an array of covariates that could be potential confounders of smoking effects. These included demographic factors such as sex, age (grouped into 4 categories: $<30,30-39,40-49$, and $\geq 50$ ), marital status (single or married/living with a partner), urbanisation status (classified into 4 groups based on urban (U) or rural (R) residency at age 10-12 and in 2005 (i.e. current) leading to lifecourse ruralites, urbanizers, de-urbanizers and urbanites [21].

Socioeconomic status (SES) was included in the analyses through three proxies: personal monthly income-very low ( $\leq 7000$ baht), low (7001 to 10,000$)$, middle $(10,001$ to $20,000)$, high (20,000 to 30,000$)$, and very high ( $\geq 30,000$ baht); educational attainment (high school, vocational study (diploma or certificate), university degree (bachelor or higher)); and household asset values (low $(\leq 30,000$ baht), medium $(30,001$ to 60,000$)$, and high $(>60,000))$. In 2005, one US dollar equalled 42 Baht.

Other factors included for analysis were drinking and the total number of chronic health conditions reported. Participants were asked if they have ever drunk alcohol. Those who answered "No, never" were then considered non-drinkers; if they reported "used to drink before but now stopped", they were classified as former drinkers. Other participants who responded either "occasional social drinker" or "current regular drinker" were classified as alcohol drinkers.

Participants were also asked to report whether they have been told by a doctor that they have one of the following conditions: diabetes (needing insulin or not), high cholesterol, high blood pressure, ischemic heart disease, stroke, cancers (liver, lung, digestive system, breast or other), goiter/thyroid abnormality, epilepsy, liver disease, chronic kidney disease, depression/anxiety, arthritis, pneumonia, chronic bronchitis, asthma, malaria, dengue fever, tuberculosis, other chronic infection, or any other diseases. Responses for all the health conditions were summed and grouped into 3 categories by number of illnesses: 0,1 , or $\geq 2$.

Body size was assessed by Body Mass Index (BMI) in $\mathrm{kg} / \mathrm{m}^{2}$, calculated as weight over height squared. Asian 
Table 1 Distribution of smoking status across socio-demographic attributes in $2005^{\text {a }}$

\begin{tabular}{|c|c|c|c|c|c|c|c|c|c|}
\hline \multirow[t]{3}{*}{ Attributes } & \multicolumn{8}{|c|}{ Smoking status } & \multirow[t]{3}{*}{ Total (N) } \\
\hline & \multicolumn{2}{|c|}{ Non-exposure } & \multicolumn{2}{|c|}{ Passive smoker } & \multicolumn{2}{|c|}{ Former smoker } & \multicolumn{2}{|c|}{ Current smoker } & \\
\hline & $\mathrm{n}$ & Row \% & $\mathrm{n}$ & Row $\%$ & $\mathrm{n}$ & Row \% & $\mathrm{n}$ & Row \% & \\
\hline Overall & 1,098 & 2.7 & 28,096 & 68.7 & 8,444 & 20.7 & 3,236 & 7.9 & 40,874 \\
\hline \multicolumn{10}{|l|}{ Age (yrs) } \\
\hline$<30$ & 368 & 2.1 & 13,847 & 78.7 & 2,298 & 13.1 & 1,088 & 6.2 & 17,601 \\
\hline $30-39$ & 444 & 3.0 & 9,732 & 65.4 & 3,358 & 22.6 & 1,357 & 9.1 & 14,891 \\
\hline $40-49$ & 215 & 3.1 & 3,958 & 56.4 & 2,175 & 31.0 & 674 & 9.6 & 7,022 \\
\hline $50+$ & 71 & 5.2 & 559 & 41.1 & 613 & 45.1 & 117 & 8.6 & 1,360 \\
\hline \multicolumn{10}{|l|}{ Sex } \\
\hline Male & 273 & 1.5 & 7,951 & 42.7 & 7,325 & 39.3 & 3,095 & 16.6 & 18,644 \\
\hline Female & 825 & 3.7 & 20,145 & 90.6 & 1,119 & 5.0 & 141 & 0.6 & 22,230 \\
\hline \multicolumn{10}{|l|}{ Marital status } \\
\hline Single & 490 & 2.5 & 15,418 & 77.1 & 2,805 & 14.0 & 1,285 & 6.4 & 19,998 \\
\hline Partnered & 587 & 2.9 & 12,190 & 60.8 & 5,397 & 26.9 & 1,861 & 9.3 & 20,035 \\
\hline \multicolumn{10}{|l|}{ Urbanisation } \\
\hline Rural-Rural & 446 & 2.4 & 12,821 & 70.0 & 3,620 & 19.8 & 1,431 & 7.8 & 18,318 \\
\hline Rural-urban & 304 & 2.6 & 7,923 & 67.2 & 2,678 & 22.7 & 881 & 7.5 & 11,786 \\
\hline Urban-rural & 45 & 2.5 & 1,144 & 64.0 & 421 & 23.6 & 177 & 9.9 & 1,787 \\
\hline Urban-Urban & 283 & 3.3 & 5,942 & 70.0 & 1,610 & 18.9 & 694 & 8.1 & 8,529 \\
\hline \multicolumn{10}{|c|}{ Personal income (Baht/month) } \\
\hline Up to 3000 & 83 & 2.4 & 2,497 & 72.4 & 525 & 15.2 & 346 & 10.0 & 3,451 \\
\hline $3000-7000$ & 267 & 2.5 & 8,294 & 76.3 & 1,597 & 14.7 & 716 & 6.6 & 10,874 \\
\hline $7000-10,000$ & 185 & 2.0 & 6,499 & 70.7 & 1,776 & 19.3 & 739 & 8.0 & 9,199 \\
\hline $10,000-20,000$ & 303 & 2.7 & 7,242 & 63.5 & 2,884 & 25.3 & 973 & 8.5 & 11,402 \\
\hline$>20,000$ & 233 & 4.5 & 3,009 & 58.1 & 1,535 & 29.6 & 401 & 7.7 & 5,178 \\
\hline \multicolumn{10}{|l|}{ Education } \\
\hline High school & 437 & 2.4 & 11,154 & 62.4 & 4403 & 24.6 & 1,887 & 10.6 & 17,881 \\
\hline Vocation & 272 & 2.5 & 7940 & 72.8 & 1,897 & 17.4 & 798 & 7.3 & 10,907 \\
\hline University & 387 & 3.2 & 8,936 & 74.5 & 2,127 & 17.7 & 545 & 4.5 & 11,995 \\
\hline \multicolumn{10}{|l|}{ Asset value } \\
\hline Low & 292 & 1.9 & 10,513 & 70.4 & 2,789 & 18.7 & 1,348 & 9.0 & 14,942 \\
\hline Middle & 340 & 2.6 & 8,894 & 68.6 & 2,734 & 21.1 & 1,002 & 7.7 & 12,970 \\
\hline High & 461 & 3.6 & 8,576 & 67.0 & 2,890 & 22.6 & 873 & 6.8 & 12,800 \\
\hline \multicolumn{10}{|l|}{ Drinking } \\
\hline Non-drinker & 579 & 5.1 & 10,268 & 91.1 & 297 & 2.6 & 129 & 1.1 & 11,273 \\
\hline Former drinker & 61 & 1.7 & 1,841 & 52.5 & 1,265 & 36.1 & 339 & 9.7 & 3,506 \\
\hline Current drinker & 456 & 1.8 & 15,903 & 61.3 & 6,834 & 26.3 & 2,743 & 10.6 & 25,936 \\
\hline \multicolumn{10}{|c|}{ No. of health condition } \\
\hline 0 & 469 & 3.2 & 10,270 & 70.7 & 2,604 & 17.9 & 1,191 & 8.2 & 14,534 \\
\hline 1 & 501 & 2.6 & 13,747 & 70.0 & 3,941 & 20.1 & 1,443 & 7.4 & 19,632 \\
\hline$\geq 2$ & 127 & 1.9 & 4,042 & 61.0 & 1,871 & 28.2 & 592 & 8.9 & 6,632 \\
\hline
\end{tabular}


Table 1 Distribution of smoking status across socio-demographic attributes in $2005^{\text {a }}$ (Continued)

\begin{tabular}{llllllllll}
\hline Body size (BMI) & & & & & & & & \\
Underweight & 139 & 2.7 & 4,431 & 85.2 & 450 & 8.6 & 183 & 3.5 & 5,203 \\
Normal & 602 & 2.8 & 15,762 & 73.5 & 3,614 & 16.8 & 1,477 & 6.9 & 21,455 \\
At risk & 176 & 2.6 & 3,863 & 57.5 & 1,955 & 29.1 & 726 & 10.8 & 6,720 \\
Obese I & 134 & 2.3 & 3,066 & 52.0 & 2,007 & 34.1 & 688 & 11.7 & 5,895 \\
Obese II & 30 & 2.8 & 661 & 60.8 & 284 & 26.1 & 113 & 10.4 & 1,088 \\
\hline
\end{tabular}

analysis restricted to cohort members assessed in 2005, 2009 and 2013. Reflecting the large sample size, all variables significantly associated with smoking status

categories were used as follows: <18.5-underweight, $\geq 18.5$ to $<23$-normal, $\geq 23$ to $<25$-overweight at risk, $\geq 25$ to $<30$-obese I, $\geq 30$-obese II.

\section{Statistical analysis}

Sociodemographic characteristics of different smoker categories were compared using bivariate frequency distributions. Similarly, the characteristics of passive smokers who reported different sources of ETS exposure were also examined.

To study the effects of smoking exposure on longitudinal wellbeing, we performed a multivariable linear regression with SF-8 summary scores at the 2013 endpoint as the outcome and 2005 baseline smoking status as the predictor. Subsequently, we performed a similar logistic regression with 2013 Kessler psychological distress as the dichotomous outcome. Finally, to study the effects of ETS exposure sources on wellbeing and psychological distress, we carried out another set of regressions (linear for SF8 as outcome and logistic for K6) with ETS exposure as predictor, restricted to passive smokers only.

All differences between means and proportions were tested by analysis of variance and the chi-square test, respectively. All p-values were 2-tailed with significance level set at $5 \%$. When important for analyses, test for linear trends were conducted and p-trend values produced. All statistical analyses were performed using STATA/SE 12.1 [22].

\section{Ethics approval}

Informed written consent was obtained from all participants. All students were advised that they could withdraw, or not participate, without any effect on their academic progress. The questionnaires never sought sensitive personal information and no biological samples were taken. Ethics approval was obtained from Sukhothai Thammathirat Open University Research and Development Institute (protocol 0522/10) and the Australian National University Human Research Ethics Committee (protocols 2004/344 and 2009/570).

\section{Results}

Characteristics of non-smokers (non-passive vs passive) and smokers (former vs current)

Among the 40,874 participants analysed, only $2.7 \%$ were never smokers with no exposure to passive smoke; the majority $(66.8 \%)$ were passive smokers (never smokers exposed to ETS) (Table 1). Approximately $21 \%$ were former smokers and only 8 \% reported smoking in 2013 .

There were clear differences in smoking status between age groups and sexes (Table 1). Older age groups were more likely to be active smokers but less likely to be exposed to passive smoke. Most active smokers (95.6\%) were males and a majority of passive smokers (79 \%) were females. The prevalence of smoking was slightly higher among married or partnered TCS members (8.9 \%) compared to members who were single (6.2\%). There was no distinct pattern between urbanisation and smoking status.

Socioeconomic status (SES) was also highly correlated to ETS exposure, positively for increasing educational attainment and negatively for rise in income or assets. There was no substantial difference in proportion of current smokers between different income levels, but education and assets both showed that higher SES groups had lower active smoking rates.

Alcohol drinkers were more likely to be active smokers and less likely to be passive smokers. Meanwhile, a higher proportion of passive smokers were observed among the healthy non-smokers (with no or only 1 health condition). Former and current smokers were more common among those with multiple health conditions. There was no noticeable difference in the distribution of body size in the non-exposure group. Passive smokers were more likely to be underweight while former and current smokers had higher prevalence of overweight at risk and obesity class I.

\section{Location of exposure to ETS and characteristics of those exposed}

For non-smokers who reported exposure to passive smoke, we tabulated the place of smoke exposure for different demographic and socioeconomic attributes (Table 2). Overall, only age, assets, income and alcohol 
Table 2 Location of ETS exposure among passive smokers by cohort member attributes in 2005

\begin{tabular}{|c|c|c|c|c|c|c|c|c|c|c|c|c|}
\hline \multirow[t]{3}{*}{ Passive smokers } & \multirow{2}{*}{\multicolumn{2}{|c|}{ Total }} & \multicolumn{10}{|c|}{$\underline{\text { Location of ETS exposure }}$} \\
\hline & & & \multicolumn{2}{|c|}{ At home } & \multicolumn{2}{|c|}{ Recreational places } & \multicolumn{2}{|c|}{ Workplace } & \multicolumn{2}{|c|}{ Transport station } & \multicolumn{2}{|c|}{ Other places } \\
\hline & $\bar{N}$ & $\%^{a}$ & $\mathrm{n}$ & $\%^{a}$ & $n$ & $\%^{a}$ & $\mathrm{n}$ & $\%^{a}$ & $\mathrm{n}$ & $\%^{a}$ & $\mathrm{n}$ & $\%^{a}$ \\
\hline Overall & 28,096 & 96.2 & 6,798 & 24.2 & 5,929 & 21.1 & 1,173 & 4.2 & 15,285 & 54.4 & 14,863 & 52.9 \\
\hline \multicolumn{13}{|l|}{ Age } \\
\hline$<30$ & 13,847 & 97.4 & 4,033 & 29.1 & 3,258 & 23.5 & 5,272 & 38.1 & 8,016 & 58.9 & 7,192 & 51.9 \\
\hline $30-39$ & 9,732 & 95.6 & 2,032 & 20.9 & 1,895 & 19.5 & 4,116 & 42.3 & 5,043 & 51.8 & 5,146 & 52.9 \\
\hline $40-49$ & 3,958 & 94.9 & 652 & 16.5 & 690 & 17.4 & 1,612 & 40.7 & 1,955 & 49.4 & 2,209 & 55.8 \\
\hline$\geq 50$ & 559 & 88.7 & 81 & 14.5 & 86 & 15.4 & 173 & 31.0 & 271 & 48.5 & 316 & 56.5 \\
\hline \multicolumn{13}{|l|}{ Gender } \\
\hline Male & 7,951 & 96.7 & 1,247 & 15.7 & 2,036 & 25.6 & 4,259 & 53.6 & 3,925 & 49.4 & 4,152 & 52.2 \\
\hline Female & 20,145 & 96.1 & 5,551 & 27.6 & 3,893 & 19.3 & 6,914 & 34.3 & 11,360 & 56.4 & 10,711 & 53.2 \\
\hline \multicolumn{13}{|l|}{ Marital status } \\
\hline Single & 15,418 & 96.9 & 3,865 & 25.1 & 3,545 & 23.0 & 5,953 & 38.6 & 8,929 & 49.9 & 8,270 & 53.6 \\
\hline Partnered & 12,190 & 95.4 & 2,841 & 23.3 & 2,291 & 18.8 & 5,015 & 41.1 & 6,083 & 57.9 & 6,373 & 52.3 \\
\hline \multicolumn{13}{|l|}{ Urbanisation } \\
\hline Rural-Rural & 12,821 & 96.6 & 3,657 & 28.5 & 2,466 & 19.2 & 4,998 & 39.0 & 6,861 & 53.5 & 6,684 & 52.1 \\
\hline Rural-urban & 7,923 & 96.3 & 1,503 & 19.0 & 1,735 & 21.9 & 3,391 & 42.8 & 4,468 & 56.4 & 4,192 & 52.9 \\
\hline Urban-rural & 1144 & 96.2 & 279 & 24.4 & 258 & 22.6 & 441 & 38.6 & 654 & 57.2 & 591 & 52.7 \\
\hline Urban-Urban & 5,942 & 95.5 & 1,314 & 22.1 & 1,429 & 24.1 & 2,235 & 37.6 & 3,156 & 53.1 & 3,285 & 55.3 \\
\hline \multicolumn{13}{|l|}{ Education } \\
\hline High school & 11,154 & 96.2 & 3,034 & 27.2 & 2,300 & 20.6 & 4,442 & 39.8 & 5,619 & 50.4 & 6,113 & 54.8 \\
\hline Diploma & 7,940 & 96.7 & 2,104 & 26.5 & 1,605 & 20.2 & 3,307 & 41.7 & 4,367 & 55.0 & 4,016 & 50.6 \\
\hline University & 8,936 & 95.8 & 1,641 & 18.4 & 2,004 & 22.4 & 3,406 & 38.1 & 5,260 & 58.9 & 4,699 & 52.6 \\
\hline \multicolumn{13}{|l|}{ Income } \\
\hline Very low & 2,497 & 96.8 & 937 & 37.5 & 634 & 25.4 & 471 & 18.9 & 1,439 & 57.6 & 1,515 & 60.7 \\
\hline Low & 8,294 & 96.9 & 2,613 & 31.5 & 1,685 & 20.3 & 3,341 & 40.3 & 4,476 & 54.0 & 4,334 & 52.3 \\
\hline Middle & 6,499 & 97.2 & 1,468 & 22.6 & 1,421 & 21.9 & 2,895 & 44.6 & 3,670 & 56.5 & 3,307 & 50.9 \\
\hline High & 7242 & 96.0 & 1245 & 17.2 & 1457 & 20.1 & 3267 & 45.1 & 3892 & 53.7 & 3,737 & 51.6 \\
\hline Very high & 3009 & 92.8 & 395 & 13.1 & 594 & 19.7 & 1116 & 37.1 & 1505 & 50.0 & 1640 & 54.5 \\
\hline \multicolumn{13}{|l|}{ Asset values } \\
\hline Low & 10,513 & 97.3 & 3,132 & 29.8 & 2,170 & 20.6 & 4,257 & 40.5 & 5,826 & 55.4 & 5,478 & 52.1 \\
\hline Middle & 8,894 & 96.3 & 2,088 & 23.5 & 1,872 & 21.1 & 3,655 & 41.1 & 4,870 & 54.8 & 4,699 & 52.8 \\
\hline High & 8,576 & 94.9 & 1,553 & 18.1 & 1,861 & 21.7 & 3,216 & 37.5 & 4,522 & 52.7 & 4,638 & 54.1 \\
\hline \multicolumn{13}{|l|}{ Drinking status } \\
\hline Non-drinker & 10268 & 94.7 & 2713 & 26.4 & 1,929 & 18.8 & 3,458 & 33.7 & 5611 & 54.7 & 5,326 & 51.9 \\
\hline Former & 1841 & 96.8 & 439 & 23.9 & 437 & 23.7 & 734 & 39.9 & 1,039 & 56.4 & 976 & 53.0 \\
\hline Current & 15903 & 97.2 & 3629 & 22.8 & 3,552 & 22.3 & 6,948 & 43.7 & 8,593 & 54.0 & 8,516 & 53.6 \\
\hline \multicolumn{13}{|c|}{ No. of health condition } \\
\hline 0 & 10270 & 95.6 & 2426 & 23.6 & 2,048 & 19.9 & 3,914 & 38.1 & 5413 & 52.7 & 5,161 & 50.2 \\
\hline 1 & 13747 & 96.5 & 3351 & 24.4 & 2,869 & 20.9 & 5,489 & 39.9 & 7,489 & 54.5 & 7,362 & 53.6 \\
\hline$\geq 2$ & 4042 & 96.9 & 1014 & 25.1 & 1000 & 24.8 & 1,748 & 43.3 & 2358 & 58.4 & 2,326 & 57.6 \\
\hline
\end{tabular}


drinking demonstrated notable differences within groups but these differences were still small ( $4 \%$ or less). The most notable finding was the limited variation in passive smoking across the range of values within each location.

All age groups reported transport stations as the most common source of passive smoke (approx. 50 \%). Proportionately more females than males reported exposure to passive smoke at home and in public transport stations. Work and recreational places of exposure had higher proportions of male than female passive smokers. For males, workplaces were the most common source of exposure to passive smoke. Females were more commonly exposed at public transport stations.

Single cohort members were more likely than married peopled to be exposed to passive smoke at home, in recreational areas and public transport stations. The reverse is true for workplaces, with married people were more vulnerable to passive smoke. SES showed different patterns for different exposure places. All three measures agreed that lower SES non-smokers were more likely to be exposed to smoke at home; the trends were monotonic for increasing SES and decreasing reported exposure (Table 2).

\section{Smoke exposure, 8-year longitudinal wellbeing, and psychological distress}

For Kessler testing, in 2013 psychological distress affected $26.8 \%$; about $4 \%$ of the cohort had serious psychological distress. For SF-8, mean scores were below 50 with physical component score (PCS) of 48.42, and mental component score (MCS) of 48.57 (Fig. 2).

Smoking status in 2005 correlated strongly with both SF-8 and Kessler 6 in 2013. In other 2005-2013 longitudinal analysis, non- smokers (i.e. 'controls') had the highest well-being score for both mental and physical components of the SF-8 (Fig. 2); they also have the lowest prevalence of psychological distress as found by Kessler 6. In general, 2005 passive smokers and former smokers were rather similar for their 2013 outcome scores. All smoker groups were similar for physical wellbeing. But mental wellbeing of current smokers was a problem as revealed in 2013 by low MCS and high prevalence of psychological distress.

As there was significant interaction between sex and smoking status, we present some 2013 analyses separately for men and women. For current smokers and controls, women had lower physical SF-8 scores than men (47.05 and 49.43 vs 48.12 and 49.84, respectively) and lower mental SF-8 scores (45.11 and 50.08 vs 47.69 and 51.47 , respectively). Similarly, SF-8 scores for other categories of smoking (passive and former) also were worse among the females. Females also had worse Kessler scores: in 2013 the prevalence of psychological distress for controls and current smokers were $20.4 \%$ and $36.9 \%$ in females and $17.0 \%$ and $31.0 \%$ in males (Fig. 2).

To explore the effects of smoking on physical and mental wellbeing, we performed two regression tests: (1) linear regression with SF-8 PCS and MCS as 2013

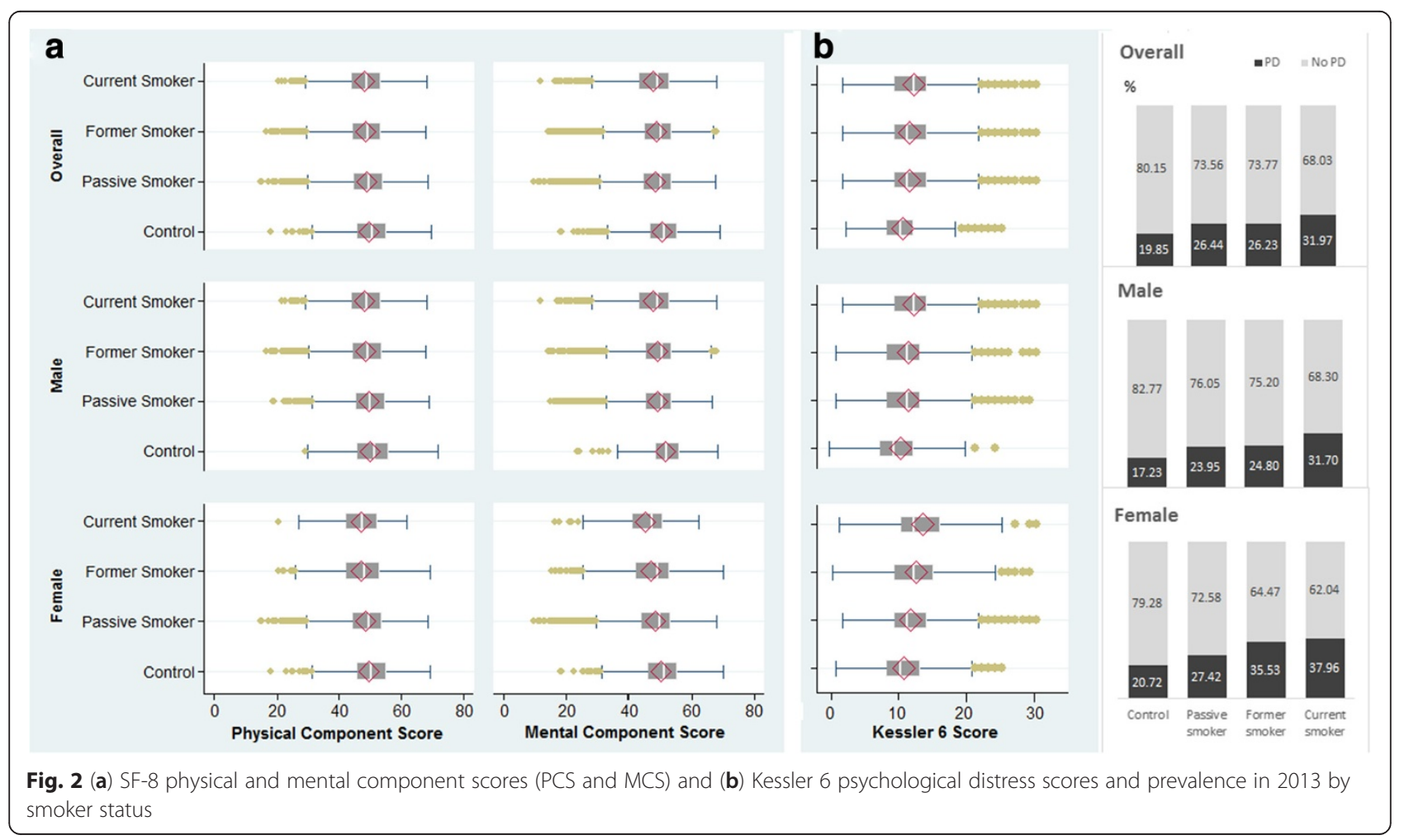


outcomes; (2) logistic regression with dichotomous psychological distress as the 2013 outcome. Both models adjusted for 2005 baseline levels of demographic attributes (age groups, marital status, urbanisation), SES (personal income, household assets value, educational attainment) and other personal factors including drinking and numbers of health conditions. All these variables were previously shown in our bivariate analysis (and in literature reviewed [5-9]) to be associated with both smoking risk and poor mental health and wellbeing.

Baseline smoking status related inversely to longitudinal wellbeing outcome (Table 3). Wellbeing was highest for the non-exposure group and decreased progressively across smoker categories-passive, former and current. The monotonic trend linking smoking and wellbeing across smoking categories had larger increments and more significance for the mental component than the physical component ( $\mathrm{p}$-trends $<0.001$ ).

Psychological distress in 2013 also displayed a strong monotonic trend relationship (p-trend $<0.001$ ) with baseline cigarette smoke exposure in 2005 (Table 3). Compared to the non-exposure group, other smoking categories had higher relative odds of psychological distress after 8 years, as follows: passive (1.29), former (1.48) and current (1.87).

Sexes differed significantly for overall wellbeing or distress. Female smokers reported worse health than their male counterparts. Males exposed to passive smoke in 2005 did not have significantly lower PCS scores, whereas females did so. Former and current male smokers reported a PCS difference of approximately 1 from the control non-exposure group. In contrast, females estimated a PCS score difference of 2 comparing similar groups.

In contrast, passive smoking appeared to affect male's mental wellbeing more than females. Exposure to any form of tobacco smoke (passive or active) significantly increased the odds of developing psychological distress in females. For males, only current smokers have significantly higher odds of developing psychological distress 8 years later (adjusted odds ratio $(\mathrm{aOR})=1.76,95 \% \mathrm{CI}$ 1.24-2.48).

Regardless of location, ETS exposure always leads to worse wellbeing and higher likelihood of psychological distress (Table 4). Males and females exhibited different patterns of responses to ETS exposure. For females,

Table 3 Baseline smoking status and 2013 8-year longitudinal wellbeing and psychological distress ${ }^{a}$

\begin{tabular}{|c|c|c|c|c|c|c|c|}
\hline \multirow{2}{*}{\multicolumn{2}{|c|}{ Smoking status $^{b}$}} & \multicolumn{4}{|c|}{ Wellbeing scores $(S F-8)^{c}$} & \multirow{2}{*}{\multicolumn{2}{|c|}{ Psychological Distress (Kessler 6) }} \\
\hline & & \multicolumn{2}{|c|}{ Physical Component } & \multicolumn{2}{|c|}{ Mental Component } & & \\
\hline & & $\overline{a M D}{ }^{e}$ & $95 \% \mathrm{Cl}$ & $\overline{a M D}{ }^{e}$ & $95 \% \mathrm{Cl}$ & $\overline{a O R^{f}}$ & $95 \% \mathrm{Cl}$ \\
\hline \multirow[t]{5}{*}{ Overall } & Control & Ref. & & Ref. & & 1.00 & . \\
\hline & Passive smoker & $-0.94^{* * *}$ & -1.37 to -0.51 & $-1.29^{* * *}$ & -1.78 to -0.80 & $1.29^{* * *}$ & 1.10 to 1.52 \\
\hline & Former smoker & $-1.46^{* * *}$ & -1.93 to -1.00 & $-1.67^{* * *}$ & -2.19 to -1.14 & $1.48^{* * *}$ & 1.25 to 1.76 \\
\hline & Current smoker & $-1.68^{* * *}$ & -2.18 to -1.17 & $-2.71^{* * *}$ & -3.28 to -2.14 & $1.87^{* * *}$ & 1.55 to 2.24 \\
\hline & p-trend & $<0.001$ & & $<0.001$ & & $<0.001$ & \\
\hline \multirow[t]{5}{*}{ Male } & Control & Ref. & & Ref. & & 1.00 & . \\
\hline & Passive smoker & -0.44 & -1.28 to 0.39 & $-1.75^{* * *}$ & -2.68 to -0.81 & 1.26 & 0.90 to 1.76 \\
\hline & Former smoker & $-0.91^{*}$ & -1.75 to -0.06 & $-1.90^{* * *}$ & -2.84 to -0.96 & 1.38 & 0.99 to 1.95 \\
\hline & Current smoker & $-1.14^{* *}$ & -2.01 to -0.28 & $-2.90^{* * *}$ & -3.87 to -1.94 & $1.76^{* *}$ & 1.24 to 2.48 \\
\hline & p-trend & $<0.001$ & & $<0.001$ & & $<0.001$ & \\
\hline \multirow[t]{5}{*}{ Female } & Control & Ref. & & Ref. & & 1.00 & . \\
\hline & Passive smoker & $-1.13^{* * *}$ & -1.64 to -0.62 & $-1.14^{* * *}$ & -1.72 to -0.56 & $1.32^{* *}$ & 1.09 to 1.59 \\
\hline & Former smoker & $-2.12^{* * *}$ & -2.78 to -1.45 & $-2.06^{* * *}$ & -2.82 to -1.31 & $1.72^{* * *}$ & 1.37 to 2.16 \\
\hline & Current smoker & $-2.15^{* *}$ & -3.46 to -0.85 & $-4.19^{* * *}$ & -5.67 to -2.71 & $2.01^{* *}$ & 1.33 to 3.02 \\
\hline & $p$-trend & $<0.001$ & & $<0.001$ & & $<0.001$ & \\
\hline
\end{tabular}

${ }^{*} p<0.05{ }^{* *} p<0.01{ }^{* * *} p<0.001$

a outcomes adjusted for demographic attributes (age group, sex, marital status, urbanisation), SES (assets, income, education), and other factors (drinking, number of health conditions, body sizes)

${ }^{b}$ smoking status:-control (not active nor passive smokers from 2005 to 2013)

- passive smoker (not active but exposed to ETS in 2005)

- former smoker (previous smokers, 2005-2013)

- current smoker (active smoker in 2013)

${ }^{c}$ multiple linear regression for SF-8 physical and mental component scores

${ }^{d}$ binary logistic regression for psychological distress (Kessler 6 14-30) vs non distress (Kessler 6 6-13)

eadjusted mean difference

fadjusted odds ratio 
Table 4 Eight year longitudinal wellbeing and psychological distress for passive smokers by location of ETS exposure ${ }^{a}$

\begin{tabular}{|c|c|c|c|c|c|c|c|}
\hline \multicolumn{2}{|c|}{ Location of ETS exposure } & \multicolumn{6}{|c|}{ Health outcomes } \\
\hline & & \multicolumn{4}{|c|}{ Wellbeing scores (SF-8) } & \multirow{2}{*}{\multicolumn{2}{|c|}{ Psychological Distress (Kessler 6) }} \\
\hline & & \multicolumn{2}{|c|}{ Physical Component } & \multicolumn{2}{|c|}{ Mental Component } & & \\
\hline & & $\overline{a M D^{d}}$ & $95 \% \mathrm{Cl}$ & $\overline{a M D^{d}}$ & $95 \% \mathrm{Cl}$ & $\mathrm{aOR}^{\mathrm{e}}$ & $95 \% \mathrm{Cl}$ \\
\hline \multirow[t]{4}{*}{ Overall } & Home & $-0.48^{* * *}$ & -0.67 to -0.28 & $-0.59 * * *$ & -0.81 to -0.37 & $1.21^{* * *}$ & 1.14 to 1.29 \\
\hline & Recreational places & $-0.28^{* *}$ & -0.48 to -0.07 & $-0.52^{* * *}$ & -0.75 to -0.29 & $1.23^{* * *}$ & 1.15 to 1.32 \\
\hline & Work & $-0.45^{* * *}$ & -0.63 to -0.29 & $-0.58^{* * *}$ & -0.77 to -0.38 & $1.23^{* * *}$ & 1.16 to 1.30 \\
\hline & Transport station & $-0.37^{* * *}$ & -0.54 to -0.21 & $-0.35^{* * *}$ & -0.53 to -0.16 & $1.10^{* * *}$ & 1.04 to 1.17 \\
\hline \multirow[t]{4}{*}{ Male } & Home & -0.20 & -0.62 to 0.23 & $-0.54^{*}$ & -1.02 to -0.07 & $1.23^{*}$ & 1.06 to 1.42 \\
\hline & Recreational places & -0.16 & -0.50 to 0.19 & $-0.58^{* *}$ & -0.96 to -0.19 & $1.37^{* * *}$ & 1.21 to 1.54 \\
\hline & Work & -0.23 & -0.54 to 0.07 & $-0.62^{* * *}$ & -0.96 to -0.27 & $1.13^{*}$ & 1.01 to 1.26 \\
\hline & Transport station & $-0.30^{*}$ & -0.60 to 0.00 & -0.24 & -0.57 to 0.01 & $1.15^{*}$ & 1.04 to 1.29 \\
\hline \multirow[t]{4}{*}{ Female } & Home & $-0.54^{* * *}$ & -0.76 to -0.31 & $-0.60^{* * *}$ & -0.85 to -0.34 & $1.21^{* * *}$ & 1.12 to 1.30 \\
\hline & Recreational places & $-0.34^{* *}$ & -0.59 to -0.09 & $-0.49 * *$ & -0.78 to -0.21 & $1.18^{* *}$ & 1.08 to 1.27 \\
\hline & Work & $-0.55^{* * *}$ & -0.75 to -0.34 & $-0.55^{* * *}$ & -0.79 to -0.32 & $1.27^{* * *}$ & 1.18 to 1.36 \\
\hline & Transport station & $-0.41^{* * *}$ & -0.61 to -0.21 & $-0.40^{* * *}$ & -0.62 to -0.17 & $1.09^{*}$ & 1.02 to 1.16 \\
\hline
\end{tabular}

${ }^{*} p<0.05{ }^{* *} p<0.01{ }^{* * *} p<0.001$

adjusted for demographic attributes (age group, sex, marital status, urbanisation), SES (assets, income, education), and other factors (drinking, number of health conditions, body sizes)

${ }^{b}$ multiple linear regression for SF-8 physical and mental component scores (PCS \& MCS)

cbinary logistic regression for psychological distress (K6 14-30) vs non distress (K6 6-13)

dadjusted mean difference

eadjusted odds ratio

exposure at all locations strongly correlated with worse physical and mental wellbeing. In contrast, among males, only ETS exposure at transport stations led to a weak association with decreased physical wellbeing; all other locations showed no statistically significant link.

For females, ETS at home was the principal source of low MCS scores. For males, exposure to ETS at workplaces led to the largest fall in MCS score. For both sexes, exposure to ETS at all sources increased the odds of reporting psychological distress. Among males, exposure at recreational areas showed the strongest association with reporting psychological distress $(\mathrm{aOR}=1.37$, 95 \% CI 1.21-1.54). Meanwhile, for females, highest likelihood of psychological distress were found amongst those reporting exposure to ETS at the workplace $(\mathrm{aOR}=1.27$, $95 \% \mathrm{CI} 1.18-1.36)$ or at home $(\mathrm{aOR}=1.21,95 \% \mathrm{CI}$ $1.12-1.30)$.

\section{Discussion}

We used the TCS, a large cohort of adults in Thailand, to investigate environmental tobacco smoke exposure and associated disparities in wellbeing and psychological distress. A high proportion of Thais, especially females, were passive smokers at home and at public transport stations. In contrast, for men passive smoking was more common at the workplace and during recreation. There was significant longitudinal association between baseline smoking status and health and wellbeing outcomes
8 years later. There were disparities in health by levels of smoke exposure with progressive worsening of the health outcomes among current, former, and passive smokers compared to the non-exposed group.

The impact of the enforcement of smoke-free legislations in Western societies has already shown benefits in reducing adverse health outcomes such as coronary heart diseases and respiratory health [23-25]; but longitudinal monitoring over time is needed for public health policy and intervention to continue minimizing the environmental smoke exposure. As well, although the ban of public smoking in confined spaces has already been introduced for over a decade and was quite successful in Western countries [26], the enforcement impact was relatively low elsewhere [27-29]. Smoking still has high prevalence in developing countries, differentially affecting the most vulnerable sub-groups who are economically worse off.

Investigation of the impact of environmental smoke exposure should not only focus on banning in public areas but also the impacts at home [30,31]. With a public ban of smoking, a study in Bangladesh has shown that a relatively large number of adults were still exposed to second-hand smoking at home [32]. So promotion of policy on smoke-free homes will improve health, in particular among the low socioeconomic groups. In Thailand, a recent study revealed that urban women were exposed to passive smoke both at home (from spouse) and the workplace and they were almost four 
times at a higher risk of breast cancers than non-exposed groups [33]. Our study showed similar results that passive smoking was still common among Thais and we further provided supporting evidence on longitudinal impacts of environmental smoke exposure on health and wellbeing.

Our current study adds to limited evidence on environmental exposure and health in transitional economies. The strength of the study lies in its large prospective longitudinal data with comprehensive baseline demographic, socioeconomic, and health background information and subsequently follow-up in 2005, 2009, and most recently in 2013.

We acknowledge some limitations of our study. First, in each 4-year follow-up wave approximately $70 \%$ of the cohort members were reached. Cohort attrition is common among longitudinal studies and we further investigated that this was generally associated with young mobile cohort members; however, we did not find these dropouts have substantive impacts on smoke exposure status. Second, our cohort members were adult open-university students residing nationwide, who shared similar demographic and geographic attributes with the Thai population; however they had relatively higher education which could lower their smoking prevalence compared to general Thais. Third, the environmental smoke exposure information was only collected at baseline in 2005 which was before the introduction of a broad ban of public smoking in Thailand [34]. We know there are enforcement problems with ETS control and our longitudinal data still captured differentials in health and wellbeing several years after the banning in hotel lobbies, pubs and bars [11, 12].

Future follow-up of the cohort will provide valuable insight into the long-term health impacts by smoking status. If Thailand actively promotes a smoke-free indoor environment, especially at home, the ETS effect reported here will attenuate and the population will benefit.

\section{Conclusions}

We add to current knowledge on the adverse impact of smoking on disparities in both physical and mental health. Active smoking affected current and former smokers but the adverse impact on health and wellbeing amongst passive smokers was also apparent even after nearly a decade of follow-up. The government effort on tobacco control should go beyond minimizing environmental smoke exposure in public. The promotion of smoking cessation programs at home could also potentially reduce disparities in health and wellbeing in middle and lower income settings such as Thailand.

\footnotetext{
Abbreviations

aMD: adjusted mean difference.; aOR: adjusted odds ratio; ETS: environmental tobacco smoke; K6: Kessler 6; MCS: Mental Component Summary; MOS SF-8: Medical Outcome Short Form-8; PCS: Physical Component Summary; SES: socioeconomic status; TCS: Thai Cohort Study.
}

\section{Competing interests}

The authors declare that they have no competing interests.

\section{Authors' contributions}

TT, VY, DC, and AS conceptualised and provided input into this study. TT analysed and drafted the manuscript. SS and AS designed and instituted the Thai Health-risk Transition research project. All authors approved the final manuscript.

\section{Acknowledgement}

This study was supported by the International Collaborative Research Grants Scheme with joint grants from the Wellcome Trust UK (GR071587MA) and the Australian National Health and Medical Research Council (268055), and as a global health grant from the NHMRC (585426). We thank the staff at Sukhothai Thammathirat Open University (STOU) who assisted with student contact and the STOU students who are participating in the cohort study.

\section{Author details}

${ }^{1}$ Research School of Population Health, College of Medicine, Biology and Environment, The Australian National University, Building 62, Mills Rd, Acton 2601, Canberra, Australia. ${ }^{2}$ Faculty of Pharmacy, Chiang Mai University, Chiang Mai, Thailand. ${ }^{3}$ School of Human Ecology, Sukhothai Thammathirat Open University, Nonthaburi, Thailand.

Received: 7 July 2015 Accepted: 30 November 2015

Published online: 08 December 2015

\section{References}

1. Potera C. Smoking and secondhand smoke: study finds no level of SHS exposure free of effects. Environ Health Perspect. 2010;118(11):A474

2. U.S. Public Health Service. The health consequences of smoking - 50 years of progress: a report of the surgeon general. Atlanta: Department of Health and Human Services; 2014.

3. World Health Organization. WHO report on the global tobacco epidemic, 2013: enforcing bans on tobacco advertising, promotion and sponsorship. Luxembourg: World Health Organization; 2013.

4. World Health Organization. WHO report on the global tobacco epidemic, 2009: implementing smoke-free environments. Geneva: World Health Organization; 2009.

5. Wilson D, Parsons J, Wakefield M. The health-related quality-of-life of never smokers, ex-smokers, and light, moderate, and heavy smokers. Prev Med. 1999;29(3):139-44.

6. Laaksonen M, Rahkonen O, Martikainen P, Karvonen S, Lahelma E. Smoking and SF-36 health functioning. Prev Med. 2006;42(3):206-9.

7. Martinez JAB, Mota GA, Vianna ÉSO, Terra Filho J, Silva GA. Rodrigues AnL. Impaired quality of life of healthy young smokers. Chest. 2004;125(2):425-8.

8. Baiardini I, Sorino C, Di Marco F, Facchini F. Smoking cessation, anxiety, mood and quality of life: reassuring evidences. Minerva Med. 2014;105(Suppl 1 to No. 5):15-21.

9. Taylor G, McNeill A, Girling A, Farley A, Lindson-Hawley N, Aveyard P. Change in mental health after smoking cessation: systematic review and meta-analysis. BMJ. 2014;348.

10. Samet JM, Hawthorne MA, Yang G. Second-hand smoke, women, and children. In: Gender, Women, and the Tobacco Epidemic. edn. Manila: World Health Organization; 2010. p. 65-101.

11. Vathesatogkit $P$, Charoenca $N$. Tobacco control: Lessons learnt in Thailand. Indian J Public Health. 2011;55(3):228.

12. Termsirikulchai L, Benjakul S, Kengganpanich M, Theskayan N, Nakju S. Thailand tobacco control country profile. Bangkok: Tobacco Control Research and Knowledge Management Center, Mahidol University; 2008. http://www.who.int/fctc/reporting/annextwothai.pdf.

13. Langhammer A, Johnsen R, Gulsvik A, Holmen T, Bjermer L. Sex differences in lung vulnerability to tobacco smoking. Eur Respir J. 2003;21(6):1017-23.

14. Sleigh AC, Seubsman SA, Bain C. Cohort profile: The Thai Cohort of 87,134 Open University students. Int J Epidemiol. 2008;37(2):266-72.

15. Seubsman SA, Yiengprugsawan V, Sleigh A, Thai Cohort Study T. A large national Thai cohort study of the health-risk transition based on Sukhothai Thammathirat Open University students. ASEAN J Open Distance Learn. 2012;4(1):58-69.

16. S-a S, Kelly M, Sleigh A, Peungson J, Chokkanapitak J, Vilainerun D. Methods used for successful follow-up in a large scale national cohort study in Thailand. BMC Res Notes. 2011;4(1):166. 
17. Ware J, Kosinski M, Dewey J, Gandek B. How to score and interpret singleitem health status measures: a manual for users of the SF-8 health survey. Lincoln and Boston: QualityMetric Inc and Health Assessment Lab; 2001.

18. Lefante Jr JJ, Harmon GN, Ashby KM, Barnard D, Webber LS. Use of the SF-8 to assess health-related quality of life for a chronically ill, low-income population participating in the Central Louisiana Medication Access Program (CMAP). Qual Life Res. 2005;14(3):665-73.

19. Bridevaux PO, Cornuz J, Gaspoz JM, Burnand B, Ackermann-Liebrich U, Schindler C, et al. Secondhand smoke and health-related quality of life in never smokers: results from the SAPALDIA cohort study 2. Arch Intern Med. 2007;167(22):2516-23.

20. Kessler RC, Galea S, Gruber MJ, Sampson NA, Ursano RJ, Wessely S. Trends in mental illness and suicidality after Hurricane Katrina. Mol Psychiatry. 2008;13(4):374-84

21. Lim LL, Kjellstrom T, Sleigh A, Khamman S, Seubsman S-A, Dixon J, Banwell C. Associations between urbanisation and components of the health-risk transition in Thailand. A descriptive study of 87,000 Thai adults. Glob Health Action. 2009;2. doi: 10.3402/gha.v2i0.1914.

22. StataCorp. Stata Statistical Software: Release 12. College Station: StataCorp LP; 2011.

23. Kelleher CC, Frazer K. An international smoking ban-how many lives will be saved? Curr Atheroscler Rep. 2014;16(6):418-24

24. Jones MR, Barnoya J, Stranges S, Losonczy L, Navas-Acien A. Cardiovascular events following smoke-free legislations: an updated systematic review and meta-analysis. Curr Environ Health Rep. 2014;1(3):239-49.

25. Rajkumar S, Stolz D, Hammer J, Moeller A, Bauer GF, Huynh CK, et al. Effect of a smoking ban on respiratory health in nonsmoking hospitality workers: a prospective cohort study. J Occup Environ Med. 2014;56(10):e86-91.

26. Kaur P, Thomas DR, Govindasamy E, Murhekar MV. Monitoring smoke-free laws in restaurants and educational institutions in Chennai, India. Natl Med J India. 2014;27(2):76-8.

27. Konstantopoulou SS, Behrakis PK, Lazaris AC, Nicolopoulou-Stamati P. Indoor air quality in a bar/restaurant before and after the smoking ban in Athens, Greece. Sci Total Environ. 2014;476:136-43.

28. Principe $R$, Paone $G$, Damante $S$, Fuselli S, Palermo P, De Marchis $L$, et al. Implementation of smoking ban: a survey in a public hospital setting. Eur J Public Health. 2014;24(3):469-71.

29. Liu R, Jiang Y, Li Q, Hammond S. Assessing exposure to secondhand smoke in restaurants and bars 2 years after the smoking regulations in Beijing, China. Indoor Air. 2014;24(4):e12091.

30. Kairouz S, Lasnier B, Mihaylova T, Montreuil A, Cohen JE. Smoking restrictions in homes after implementation of a smoking ban in public places. Nicotine Tob Res. 2014; doi: 10.1093/ntr/ntu125.

31. Ye X, Yao Z, Gao Y, Xu Y, Xu Y, Zhu Z, et al. Second-hand smoke exposure in different types of venues: before and after the implementation of smoke-free legislation in Guangzhou, China. BMJ. 2014;4(2):e004273.

32. Abdullah AS, Driezen P, Sansone G, Nargis N, Hussain GA, Quah AC, et al. Correlates of exposure to secondhand smoke (SHS) at home among non-smoking adults in Bangladesh: findings from the ITC Bangladesh survey. BMC Pulm Med. 2014;14(1):117-27.

33. Pimhanam C, Sangrajrang S, Ekpanyaskul C. Tobacco smoke exposure and breast cancer risk in Thai urban females. Asian Pac J Cancer Prev. 2014;15(17):7407.

34. World Health Organization: Country Office for Thailand. Thailand smoke free environment development. 2015. http://www.searo.who.int/thailand/areas/ smokefree/en/. Accessed 07 Jul 2015.

\section{Submit your next manuscript to BioMed Central and we will help you at every step:}

- We accept pre-submission inquiries

- Our selector tool helps you to find the most relevant journal

- We provide round the clock customer support

- Convenient online submission

- Thorough peer review

- Inclusion in PubMed and all major indexing services

- Maximum visibility for your research

Submit your manuscript at www biomedcentral com/submit 